\title{
Recessions and mortality: subtle but informative effects
}

Research on the health consequences of economic downturns has focused on the unemployed population. Losing one's job is stressful, and undermines a sense of personal worth, besides the effect on earnings [A: edit Q?]. The most extreme manifestation of the negative errect of unemployment is its association with suicide, reported in studies at both individual ${ }^{1}$ and population ${ }^{2,3}$ [A: We have exceeded the maximum number of references, could we delete one of these two?] levels. Mortality from cardiovascular disease and other conditions is also increased in unemployed people. ${ }^{1}$

Therefore, it appears paradoxical that when unemployment increases in a country, mortality of the population as a whole tends to decline. This is the finding of a study by Enrique Regidor and colleagues, ${ }^{4}$ which follows up the entire Spanish population aged 10-74 years in 2001 for 10 years. Mortality was examined in the period before the recent recession (2004-07) and then afterwards (2008-11). The rate of decline in total mortality following the recession was found to be steepest in those who were least socioeconomically advantaged.

Overall, this new study confirms much of what has been established in a research field going back almost a century:5.6 [A: Could we delete one of these two refrences?] that total mortality declines in recessions and rises transiently when the economy expands. This effect is described as procyclical. ${ }^{7}$ These findings have been interpreted by some as minimising the negative impact of unemployment on individuals. However, this view fails to distinguish between the impact of unemployment on the unemployed people per se, and the association of mortality with macro-economic conditions in whole populations, as proxied by a country's unemployment rate. ${ }^{8}$

There are several reasons why a recession would affect working age mortality in the population as a whole aside from suicide. Particularly for manual workers, lower levels of industrial production and construction can result in reduced exposure to workplace hazards. Although a recession could result in some employers taking shortcuts with health and safety measures, the net effect of the recession is the reduction of industrial injuries and fatalities, as has been seen in Spain. ${ }^{9}$

Declines in mortality during recessions have $[\mathrm{A}: \mathrm{D}$ ?] been found among people well above retirement age. ${ }^{10}$ This finding points to effects of the recession that touch all age groups regardless of labour market involvement [A: edit ok?] pollution could be one of these effects: variation in purticulates and nitrogen oxides have been associated with fluctuations in mortality from cardiovascular and respiratory disease in old ages as well as working ages. ${ }^{11}$ Using satellite data, a study ${ }^{12}$ from the USA showed profound effects of the 2008 recession on nitrogen dioxide plumes above cities. As might be expected, Regidor and colleagues replicate the widely observed $^{2}$ fall in mortality from road traffic injuries. A detailed analysis of the reduction in this cause during the 2008 economic downturn in the USA suggested that the key factor was changes in the mix of vehicle types on the road. ${ }^{13}$ Reductions in air pollution levels and hazardous traffic could be expected to reduce mortality risk most among the least advantaged in society.

It has been suggested that the procyclical, macroeconomic effects on mortality have diminished over recent decades. ${ }^{14}$ Interventions to reduce air pollution, control smoking, and improve levels of workplace and social protection might have contributed to this decreased effect. However, there could be a more important explanation. Cardiovascular disease has been the principal driver of the associations of total mortality with macro-economic conditions, whereas cancer has been little implicated. Since the 1970s the balance of total deaths due to cardiovascular disease and cancer has changed in high-income countries, driven principally by the steep decline in cardiovascular deaths [A: is this what you meant by "the former"?]. ${ }^{15}$ Thus pro-cyclical effects might diminish as a result of changes in the cause-specific composition of total mortality.

The most compelling evidence that social and economic changes can have powerful and immediate effects on mortality of nation states comes from the impact of the fall of the Berlin wall and its aftermath on the former communist countries of Europe. ${ }^{16}$ These effects were much larger and in the opposite direction to those seen as a result of recessions in western countries, and cannot be explained in purely macro-economic terms. The case of Russia in the 1990s attests to the potentially catastrophic negative effect on mortality of a breakdown in the functioning of the state and in the structures that make 
daily life predictable and contained. ${ }^{17}$

With the current outlook for the world economy looking increasingly uncertain, the health effects of macro-economic policies should rightly be kept in the spotlight. But it is important to put things in context. It is remarkable that over the past 60 years life expectancy in all high-income western countries has increased steadily, ${ }^{16}$ with any effect of the 2008 or earlier recessions being almost invisible. This is not to be complacent, for these relatively subtle effects of macroeconomic circumstances on mortality point to deaths that are clearly preventable if society chose to act.

\section{David A Leon}

London School of Hygiene \& Tropical Medicine, Keppel St, London WC1E 7HT, UK

A: Please supply an email address]

declare no competing interests.

1 Vagero D, Garcy AM. Does unemployment cause long-term mortality? Selection and causation after the 1992-96 deep Swedish recession. EurJ Public Health 2016; published online April 16. http://dx.doi. org/10.1093/eurpub/ckw053.

2 Stuckler D, Basu S, Suhrcke M, Coutts A, McKee M. The public health effect of economic crises and alternative policy responses in Europe: an empirical analysis. Lancet 2009; 374: 315-23.

3 Isabel RP, Miguel RB, Antonio RG, Oscar MG. Economic crisis and suicides in Spain. Socio-demographic and regional variability. Eur J Health Econ 2016; published online March 2. DOI: 10.1007/s10198-016-0774-5.
4 Regidor E, Vallejo F, Tapia Granados JA, Viciana-Fernandez FJ, de la Fuente L, Barrio G. Mortality decrease according to socioeconomic groups during the economic crisis in Spain: a cohort study of 36 million people. Lancet 2016 [Ed: to update].

5 Ogburn WF, Thomas DS. The influence of the business cycle on certain social conditions. J Am Stat Assoc 1922; 18: 324-40

6 Tapia Granados JA. Commentary: William Ogburn, Dorothy Thomas and the influence of recessions and expansions on mortality. Int J Epidemiol 2015; 44: 1484-90.

7 Stuckler D, Reeves A, Karanikolos M, McKee M. The health effects of the global financial crisis: can we reconcile the differing views? A network analysis of literature across disciplines. Health Econ Policy Law 2015; 10: 83-99.

8 Tapia Granados JA. Increasing mortality during the expansions of the US economy, 1900-1996. Int J Epidemiol 2005; 34: 1194-202.

9 Fernández-Muñiz B, Montes-Peón JM, Vázquez-Ordás CJ. Occupational accidents and the economic cycle in Spain 1994-2014 Safety Science 2016.

10 Ruhm CJ. A healthy economy can break your heart. Demography 2007; 44: 829-48.

11 Su C, Hampel R, Franck U, et al. Assessing responses of cardiovascular mortality to particulate matter air pollution for pre-, during- and post-2008 Olympics periods. Environ Res 2015; 142: 112-22.

12 de Foy B, Lu Z, Streets DG. Impacts of control strategies, the Great Recession and weekday variations on $\mathrm{NO} 2$ columns above North American cities. Atmospheric Environment 2016; 138: 74-86.

13 He MM. Driving through the Great Recession: why does motor vehicle fatality decrease when the economy slows down? Soc Sci Med 2016; 155: 1-11.

14 Ruhm CJ. Recessions, healthy no more? J Health Econ 2015; 42: 17-28.

15 Ezzati M, Obermeyer Z, Tzoulaki I, Mayosi BM, Elliott P, Leon DA. Contributions of risk factors and medical care to cardiovascular mortality trends. Nat Rev Cardiol 2015; 12: 508-30.

16 Leon DA. Trends in European life expectancy: a salutary view. Int J Epidemiol 2011; 40: 271-77.

17 Leon DA, Shkolnikov VM. Social stress and the Russian mortality crisis. JAMA 1998; 279: 790-91. 